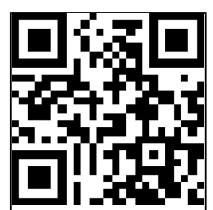

Editor's choice Scan to access more free content

\title{
The impact of psychological readiness to return to sport and recreational activities after anterior cruciate ligament reconstruction
}

\author{
Clare L Ardern, ${ }^{1,2}$ Annika Österberg, ${ }^{2,3}$ Sofi Tagesson, ${ }^{2}$ Håkan Gauffin, ${ }^{4}$ \\ Kate E Webster, ${ }^{1}$ Joanna Kvist ${ }^{2}$
}

- Additional material is published online only. To view please visit the journal online (http://dx.doi.org/10.1136/ bjsports-2014-093842).

${ }^{1}$ School of Allied Health, Faculty of Health Sciences, La Trobe University, Melbourne, Victoria, Australia ${ }^{2}$ Division of Physiotherapy, Linköping University, Linköping, Sweden

${ }^{3}$ Centre for Clinical Research Sörmland, Uppsala University, Eskilstuna, Sweden ${ }^{4}$ Orthopaedic Department, Linköping University, Linköping, Sweden

\section{Correspondence to} Dr Clare Ardern, School of Allied Health, Faculty of Health Sciences, La Trobe University, Bundoora, VIC 3086, Australia; c.ardern@latrobe.edu.au

Accepted 22 September 2014 Published Online First 7 October 2014
CrossMark

To cite: Ardern $\mathrm{CL}$, Österberg A, Tagesson S, et al. Br J Sports Med 2014;48:1613-1619.

\begin{abstract}
Background This cross-sectional study aimed to examine whether appraisal of knee function, psychological and demographic factors were related to returning to the preinjury sport and recreational activity following anterior cruciate ligament $(\mathrm{ACL})$ reconstruction. Method 164 participants completed a questionnaire battery at $1-7$ years after primary $A C L$ reconstruction. The battery included questionnaires evaluating knee selfefficacy, health locus of control, psychological readiness to return to sport and recreational activity, and fear of reinjury; and self-reported knee function in sport-specific tasks, knee-related quality of life and satisfaction with knee function. The primary outcome was returning to the preinjury sport or recreational activity.
\end{abstract}

Results At follow-up, 40\% (66/164) had returned to their preinjury activity. Those who returned had more positive psychological responses, reported better knee function in sport and recreational activities, perceived a higher knee-related quality of life and were more satisfied with their current knee function. The main reasons for not returning were not trusting the knee $(28 \%)$, fear of a new injury (24\%) and poor knee function (22\%).

Psychological readiness to return to sport and recreational activity, measured with the ACL-Return to Sport after Injury scale (was most strongly associated with returning to the preinjury activity). Age, sex and preinjury activity level were not related.

Conclusions Less than $50 \%$ returned to their preinjury sport or recreational activity after $\mathrm{ACL}$ reconstruction.

Psychological readiness to return to sport and recreation was the factor most strongly associated with returning to the preinjury activity. Including interventions aimed at improving this in postoperative rehabilitation programmes could be warranted to improve the rate of return to sport and recreational activities.

\section{INTRODUCTION}

An important objective of anterior cruciate ligament (ACL) reconstruction is to enable patients to return to their preinjury sport or recreational activity. Despite this, the focus of the orthopaedic literature has been on evaluating impairment-based outcomes, such as knee stability, after reconstruction as a measure of the success of the surgery, while non-physical factors, including psychological factors, have been under-researched. ${ }^{1}{ }^{2}$ From an impairment perspective, patients recover physical function well after surgery. ${ }^{3}$ However, between one-third and two-thirds of patients may not return to participation in their preinjury activity, despite being physically recovered, when evaluated with standard objective instruments. ${ }^{3-6}$

Objective physical recovery and returning to the preinjury sport and recreational activity may not necessarily coincide after ACL reconstruction, ${ }^{4} 7$ which raises the question of what other factors could impact on returning. Recent research has suggested that psychological factors may be important influences on returning to sport and recreation after athletic injury, ${ }^{8}{ }^{9}$ but cautioned that because there are few studies examining the relationship between psychological factors and returning to sport and recreation, more research is needed to facilitate more definitive conclusions. ${ }^{9}$ The only meta-analysis of the relationship between psychological factors and returning to the preinjury sport following ACL reconstruction found large effects (standardised mean difference $\geq 0.9$ ) for positive psychological responses favouring returning to sport, based on four studies. ${ }^{9}$

Psychological readiness to return to sport, recovery expectations, sport locus of control and selfefficacy regarding knee function are psychological factors that have been shown to predict returning to the preinjury sport at 12 months after ACL reconstruction; $5^{10}$ and self-efficacy of knee function, measured before surgery, has been shown to predict returning to physical activity at 1 year after ACL reconstruction. ${ }^{10}$ Fear of sustaining another injury has also been associated with not returning to the preinjury physical activity for up to 7 years after reconstruction, ${ }^{4} 1112$ and is a common reason cited by athletes for not returning to sport and recreational activities. ${ }^{3} 41314$

People who did not have an ACL reconstruction after their ACL injury reported a positive relationship between their physical knee function and confidence in their knee, and stated that this had a positive impact on their participation in sport and recreational activities. ${ }^{14}$ However, to the best of our knowledge, this relationship has not been investigated in people who have had an ACL reconstruction. Previous studies have found no relationship between objective measures of physical impairment and patient-reported knee function following ACL reconstruction. ${ }^{15-17}$ In light of this, and the potential for an individual's report of knee function to impact on their return to sport and recreational activity after an ACL injury, it may be suggested that it is important to consider the impact of appraisals of knee function on returning to preinjury activity after reconstruction. 
Participation in sport and recreational activity is complex and multifactorial; and there may be individual differences in the factors that impact on returning to participation in the preinjury activity following ACL reconstruction. Therefore, taking account of a range of psychological and contextual factors may improve our understanding of what influences returning to the preinjury activity, and help direct rehabilitation interventions aimed at improving the return to preinjury sport and recreational activity rate. Therefore, the aim of the current study was to examine whether appraisal of knee function, psychological and demographic factors were related to returning to the preinjury sport and recreational activity after ACL reconstruction.

\section{METHOD}

Design

This was a cross-sectional study, approved by the Regional Ethics Committee (Linköping University approval number: 2012/425-32). Written, informed consent to participate was obtained from all participants.

\section{Participants}

Participants were identified from two orthopaedic units (one tertiary teaching hospital and two local hospitals) in southeastern Sweden. The medical records of all patients with a knee injury diagnosis code of chronic instability of the knee, dislocation of the knee, sprain or strain involving cruciate ligament of knee, and injury to multiple structures of the knee recorded (International Classification of Diseases 10 codes M23.5, S83.1, S83.5, S83.7), and who were seen at the orthopaedic units between January 2004 and December 2008 were screened. Patients with nonoperative treatment, bilateral injuries, revision surgery, other associated ligament pathology that required surgical treatment at the time of ACL reconstruction, or who had Outerbridge ${ }^{18}$ grade III or IV chondral injury were excluded (figure 1) to identify patients with a primary, uncomplicated ACL reconstruction. A total of 346 of 1447 patients met the inclusion criteria of age between 18 and 45 years at the time their medical record was reviewed, and 1-7 years after an isolated primary unilateral ACL reconstruction performed at either of the two orthopaedic units. Five patients declined to participate and 21 patients were unable to be contacted. Twelve patients had sustained a new knee injury between surgery and follow-up (figure 1).

Of the 182 patients (59\% of 308 ) who responded, 164 were included in the final analysis for the current study. Data from 18 participants were excluded because the participants either did not participate in sport or recreational activity prior to their knee injury $(n=9)$, or because they were active in recreational activities with a preinjury Tegner Activity Scale ${ }^{19}$ score of less than $4(n=9$; figure 1$)$. An updated Tegner Activity Scale ${ }^{20}$ with sports that were not included in the original scale was used to grade preinjury activity level in the current study. The scale rates activity level according to functional demands on the knee on an 11-level scale (scored from 0 to 10). Level 10 indicates the highest functional demand such as national or international level competitive football; level 7 indicates sports such as competitive tennis and recreational football; level 4 indicates sports such as recreational cycling or cross country skiing, and moderately heavy labour work; levels 3 to 1 indicate walking for recreation and light labour to sedentary work; and level 0 indicates no participation in physical activity due to knee problems. ${ }^{20}$

\section{Procedures}

A battery of patient-reported outcomes, which took 30-40 min to complete, was sent by post to all eligible participants. Up to three written reminders were sent over a 6-week period ( 2 weeks apart). Participants who had not completed the battery of patient-reported outcomes within 2 weeks were sent a reminder letter (and a new battery of outcomes). If they still had not responded within 2 weeks after the first reminder was sent, a second reminder letter was sent. A third and final reminder letter was sent to participants who had not returned the patientreported outcomes within 6 weeks from the date the original questionnaire pack was sent. Participants completed the battery of outcomes, on average, at 35 months (range 12-81 months) after their ACL reconstruction surgery.

\section{Outcome measures}

The primary outcome was return to the preinjury sport or recreational activity. Participants reported the main activity they participated in before their ACL injury, and answered the question 'Have you returned to your previous activity?' Participants who reported that they had not returned to their preinjury activity were asked to rank the following reasons for not returning from most important to least important: 'poor knee function', 'do not trust the knee', 'fear getting a new injury', 'team or training has changed', 'family commitments', 'work commitments' and 'other reasons'.

A battery of validated patient-reported outcomes was used to evaluate factors that may influence participation in the preinjury activity. The Swedish versions of all outcomes were used. Factors were chosen based on the researchers' previous experience in the area of returning to sport and recreational activity after ACL reconstruction, and the findings of recently published literature. A systematic review of psychological factors associated with returning to sport following athletic injury ${ }^{8}$ was used to guide the selection of psychological factors, based on the theoretical constructs of competence, autonomy and relatedness. Psychological factors and appraisal of knee function factors with evidence of construct or known-groups validity in ACL reconstruction populations were chosen (online supplementary appendix). For analysis, the factors evaluated were grouped as psychological factors, appraisal of knee function factors and demographic factors. A detailed description of patient-reported outcomes, including their psychometric properties, is provided in the online supplementary appendix.

\section{Explanatory variables}

\section{Psychological factors}

The Knee Self-Efficacy Scale (K-SES) ${ }^{21}$ was used to evaluate participants' self-efficacy of current and future knee function.

The Multidimensional Health Locus of Control C-form (MHLC-C) $)^{22}$ was used to evaluate the extent to which participants perceived their health was determined by their own behaviour, or by external events or people. The MHLC comprises four domains-Internal, Chance, Doctors and Others, reported as separate scores.

The ACL-Return to Sport after Injury scale (ACL-RSI) ${ }^{23} 24$ was used to evaluate psychological readiness to return to sport and recreational activity.

The Tampa Scale for Kinesiophobia (TSK), ${ }^{25}$ adapted by Kvist et $a l^{11}$ for use with patients with ACL injury, was used to evaluate fear of reinjury.

\section{Appraisal of knee function}

The Sport (five items) domain of the Knee Injury and Osteoarthritis Outcome Score (KOOS) ${ }^{26}$ was used to evaluate participants' perceptions of knee function during sport and 


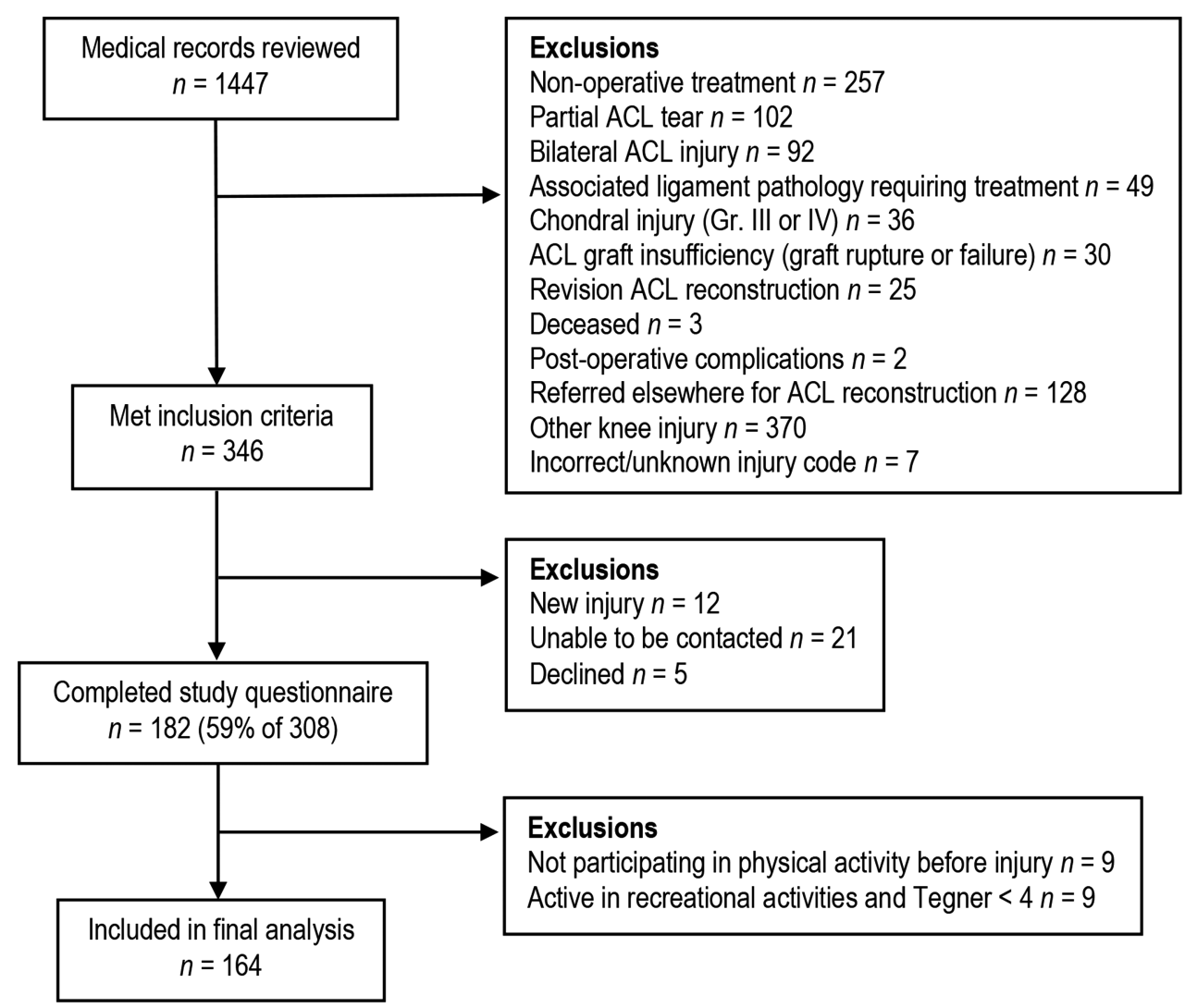

Figure 1 Participant identification ( $A C L$, anterior cruciate ligament; Gr., grade).

recreational activities. The Quality of Life (four items) domain of the KOOS was used to evaluate knee-related quality of life.

The ACL-Quality of Life scale (ACL-QoL) ${ }^{27}$ was used to evaluate knee-related quality of life specifically related to ACL injury.

Participants also rated their overall satisfaction with their current level of knee function on a 10-point, numerical scale written specifically for the current study.

\section{Demographic factors}

Age at follow-up, sex and the preinjury activity level, selfreported by participants as elite, subelite competitive or recreational level activity, were analysed.

\section{Statistical analysis}

All analyses were completed using SPSS V.20.0 (IBM Corp, Armonk, New York, USA); and a list-wise deletion approach was used to deal with missing data. The psychological factors evaluated were knee self-efficacy, health locus of control, psychological readiness to return to sport and recreational activity, and fear of reinjury. The appraisal of knee function factors were knee function during sport and recreational activities, knee-related quality of life and satisfaction with knee function.

\section{Between-groups analyses}

A $p$ value of $\leq 0.05$ was used to indicate statistical significance. Descriptive statistics were calculated for all explanatory variables and compared between participants who had and had not returned to their preinjury sport or recreational activity, to give an overall impression of differences in individual patientreported outcomes between those who had and had not returned to activity. Age was dichotomised based on the median age of the cohort. Between-groups comparisons were made using $\chi^{2}$ tests, and independent samples $t$ tests or Mann-Whitney $U$ tests as appropriate. $\alpha$ Corrections for multiple comparisons were made using Benjamini and Hochberg's ${ }^{28}$ false-discovery rate method, which has been advocated for use in health research in place of Bonferroni adjustments. ${ }^{29}$ Unadjusted and adjusted $\mathrm{p}$ values were calculated and presented to provide an indication of the likelihood of type I and II error rates; given that it has been previously argued that minimisation of the likelihood of type II error is preferable in exploratory research. ${ }^{3031}$

\section{Multivariable analyses}

Binary logistic regression was used to determine the factors associated with returning to the preinjury sport or recreational activity. Return to the preinjury activity (yes or no) was the outcome variable.

A two-stage process was used to determine the psychological and appraisal of knee function explanatory variables to be included in the final model. First, simple regression analyses, where individual explanatory variables were regressed on the outcome variable were used to identify the psychological and appraisal of knee function factors to be included in the second stage. A significance level of $\leq 0.10^{32}$ was used to decide whether individual variables were retained. At this stage, all subscales of the MHLC scale (Internal, Chance, Doctors and Others) were excluded from further analysis. The explanatory variables that were retained were checked for multicollinearity using the linear regression method. ${ }^{33}$ A Variance Inflation Factor of $>5$ was used to denote significant multicollinearity. The ACL-QoL scale was excluded from further analyses due to significant multicollinearity. Then, the remaining explanatory variables were entered into a backward stepwise model. A significance level of $\leq 0.05$ was used to identify variables that 
would be retained for the final model. Outliers were excluded based on a standardised residual of $>3$. Using this criterion, one outlier was excluded from the final model.

For the final model, the explanatory variable(s) that were retained were entered with the demographic age, sex and preinjury activity level. Time between surgery and follow-up (months) was also included as an independent adjusting variable in the final model; interactions between explanatory variables were also examined.

\section{RESULTS}

Ninety-nine men (median age 28 years) and 65 women (median age 24 years) with a median age of 26 years (range 18-45 years) at the time of follow-up were included. The majority of participants were active at a subelite competitive level (64\%) prior to their ACL injury; 24 participants (15\%) were active at an elite competitive level and the remaining $35(21 \%)$ were active at a recreational level. At the time of ACL injury, participants were most commonly participating in football $(\mathrm{n}=83,52 \%)$, floorball $(n=20,12 \%)$ or handball $(n=8,5 \%)$. At follow-up, 66 participants $(40 \%)$ had returned to their preinjury sport or recreational activity, and the rate of return to activity was not associated with age, sex or preinjury activity level (table 1).

Among the top three sports most frequently participated in (football, floorball and handball), approximately one in three people had returned to their preinjury activity participation (table 2).

The three most common reasons for not returning were a lack of trust in the knee ( $\mathrm{n}=25$ of $88,28 \%)$, fear of sustaining a new injury $(\mathrm{n}=21$ of $88,24 \%)$ and poor knee function $(\mathrm{n}=19$ of $88,22 \%$; table 3 ).

\section{Between-group comparisons}

There were significant differences in psychological and appraisal of knee function factors between participants who had and had not returned to their previous sport or recreational activity (table 4). Participants who had returned to their previous activity reported higher knee self-efficacy (K-SES); greater psychological readiness to return to sport and recreational activity

Table 1 Demographic data for participants who had and had not returned to preinjury sport or recreational activity

\begin{tabular}{|c|c|c|c|}
\hline \multirow[b]{2}{*}{ Variable } & \multicolumn{2}{|c|}{$\begin{array}{l}\text { Returned to preinjury } \\
\text { activity }\end{array}$} & \multirow[b]{2}{*}{$\begin{array}{l}\mathrm{p} \\
\text { Value }\end{array}$} \\
\hline & $\begin{array}{l}\text { Yes } \\
(n=66)\end{array}$ & No $(n=98)$ & \\
\hline $\begin{array}{l}\text { Time from surgery to follow-up, months, } \\
\text { mean (SD) (range 12-81 months) }\end{array}$ & $34.3(15.1)$ & $35.8(15.3)$ & 0.54 \\
\hline Age group (years) & & & 0.57 \\
\hline $18-26$ & $36(42 \%)$ & $49(58 \%)$ & \\
\hline $27-45$ & $30(38 \%)$ & $49(62 \%)$ & \\
\hline Sex & & & 0.96 \\
\hline Male & $40(40 \%)$ & $59(60 \%)$ & \\
\hline Female & $26(40 \%)$ & $39(60 \%)$ & \\
\hline Preinjury activity level ${ }^{*}$ & & & 0.89 \\
\hline Elite & $10(42 \%)$ & $14(58 \%)$ & \\
\hline Competitive & $43(42 \%)$ & $60(58 \%)$ & \\
\hline Recreational & $13(37 \%)$ & $22(63 \%)$ & \\
\hline
\end{tabular}

Table 2 Frequency of returning to preinjury sport or recreation activities by sport

\begin{tabular}{|c|c|c|c|}
\hline Sport & $\begin{array}{l}\text { Number of participants } \\
\text { in preinjury activity, } \% \\
\text { of total sample }\end{array}$ & $\begin{array}{l}\text { Yes } \\
n=65^{*}\end{array}$ & $\begin{array}{l}\text { No } \\
n=96 t\end{array}$ \\
\hline Football & $83(52)$ & $29(35)$ & $54(65)$ \\
\hline Floorball & $20(12)$ & $6(30)$ & $14(70)$ \\
\hline Handball & $8(5)$ & $3(38)$ & $5(62)$ \\
\hline Martial artsł & $6(4)$ & 4 & 2 \\
\hline Motocross§ & $6(4)$ & 4 & 2 \\
\hline Running & $6(4)$ & 2 & 4 \\
\hline Basketball & $5(3)$ & 0 & 5 \\
\hline Horse-riding & $5(3)$ & 4 & 1 \\
\hline Gymnasium exercises & $4(2)$ & 3 & 1 \\
\hline Hockey** & $3(2)$ & 2 & 1 \\
\hline Athletics & $2(1)$ & 2 & 0 \\
\hline Orienteering & $2(1)$ & 2 & 0 \\
\hline Skateboard & $2(1)$ & 0 & 2 \\
\hline Snow sports & $2(1)$ & 1 & 1 \\
\hline Squash & $2(1)$ & 1 & 1 \\
\hline Bandy & $1(<1)$ & 0 & 1 \\
\hline Cycling & $1(<1)$ & 0 & 1 \\
\hline Team gymnastics & $1(<1)$ & 1 & 0 \\
\hline Tennis & $1(<1)$ & 1 & 0 \\
\hline Volleyball & $1(<1)$ & 0 & 1 \\
\hline \multicolumn{4}{|c|}{$\begin{array}{l}\text { The percentage of participants who had returned and not returr } \\
\text { presented in parentheses. } \\
{ }^{*} \text { One participant did not report their preinjury physical activity. } \\
\text { †Two participants did not report their preinjury physical activity } \\
\text { fIncludes karate, jujitsu and judo. } \\
\text { §Includes short-distance and endurance-distance competition. } \\
\text { १Includes aerobics and weight training. } \\
{ }^{* *} \text { Includes one ice hockey referee. }\end{array}$} \\
\hline
\end{tabular}

(ACL-RSI); and lower fear of reinjury (TSK). They also reported better knee function in sport and recreational activities (KOOS_Sport), higher knee-related quality of life (ACL-QoL, KOOS_QoL) and greater satisfaction with knee function (table 4$)$.

\section{Factors associated with returning to the preinjury sport and recreational activity}

Psychological readiness to return to sport and recreational activity (ACL-RSI) was the only explanatory variable that met our

Table 3 Reasons for not returning to the preinjury sport or recreational activity after anterior cruciate ligament reconstruction (proportion of responses ranked by participants as most important)

\begin{tabular}{llc}
\hline & $\mathbf{n}$ & Per cent \\
\hline Do not trust the knee & 25 & 28 \\
Fear getting a new injury & 21 & 24 \\
Poor knee function & 19 & 22 \\
Family or work commitments & 9 & 10 \\
Other reasons & 9 & 10 \\
Change in team or coach & 5 & 6 \\
Total & $88^{*} \dagger$ & 100 \\
\hline${ }^{*}$ Data were excluded from six participants who ranked more than 1 reason as the \\
most important for not returning. \\
†Missing data from four participants.
\end{tabular}


Table 4 Comparisons of psychological and appraisal of knee function between participants who had and had not returned to their preinjury sport or recreational activity

\begin{tabular}{|c|c|c|c|c|c|c|}
\hline Variable & $\begin{array}{l}\text { Overall, } \\
\text { mean (SD) }\end{array}$ & $\begin{array}{l}\text { Returned to preinjury } \\
\text { activity }(n=66)\end{array}$ & $\begin{array}{l}\text { Not returned to preinjury } \\
\text { activity }(n=98)\end{array}$ & $\begin{array}{l}\text { Mean difference } \\
(95 \% \mathrm{Cl})\end{array}$ & p Value & $\begin{array}{l}\text { FDR-adjusted } \\
\text { significance, } q\end{array}$ \\
\hline K-SES $(0-10)(n=157)$ & $6.9(2.1)$ & $7.7(1.8)$ & $6.4(2.1)$ & $1.3(0.7$ to 2.0$)$ & $<0.001$ & $<0.001$ \\
\hline MHLC_internal (6-36) $(n=156)$ & $25.8(5.5)$ & $25.7(5.3)$ & $25.9(5.7)$ & $-0.2(-2.0$ to 1.5$)$ & 0.68 & 0.69 \\
\hline MHLC_chance $(6-36)(n=155)$ & $13.0(5.2)$ & $13.2(5.3)$ & $12.9(5.2)$ & $0.3(-1.4$ to 2.1$)$ & 0.69 & 0.69 \\
\hline MHLC_doctors $(6-18)(n=157)$ & $11.7(3.1)$ & $11.2(3.0)$ & $12.0(3.2)$ & $-0.8(-1.8$ to 0.2$)$ & 0.16 & 0.22 \\
\hline MHLC_others (6-18) (n=157) & $6.9(2.1)$ & $6.8(2.1)$ & $7.1(2.2)$ & $-0.3(-1.0$ to 0.4$)$ & 0.34 & 0.42 \\
\hline ACL-RSI $(1-10)(n=163)$ & $4.9(2.1)$ & $6.2(2.0)$ & $4.5(2.1)$ & $1.6(1.0$ to 2.3$)$ & $<0.001$ & $<0.001$ \\
\hline TSK $(17-68)(n=148)$ & $35.6(8.0)$ & $32.1(7.2)$ & $37.8(7.9)$ & $-5.6(-8.1$ to -3.1$)$ & $<0.001$ & $<0.001$ \\
\hline KOOS_Sport $(0-100)(n=157)$ & $70.6(24.8)$ & $77.5(22.3)$ & $65.8(25.5)$ & $11.7(4.1$ to 19.3$)$ & $<0.01$ & $<0.001$ \\
\hline KOOS_QoL (0-100) (n=159) & $62.0(22.7)$ & $70.0(19.8)$ & $56.6(23.1)$ & 13.4 (6.7 to 20.2$)$ & $<0.001$ & $<0.001$ \\
\hline ACL-QoL (1-10) $(n=155)$ & $6.5(2.0)$ & $7.5(1.8)$ & $5.9(1.9)$ & 1.6 (1.0 to 2.2$)$ & $<0.001$ & $<0.001$ \\
\hline Satisfaction (1-10) (n=164) & $6.0(2.7)$ & $7.0(2.4)$ & $5.3(2.6)$ & $1.6(0.8$ to 2.4$)$ & $<0.001$ & $<0.001$ \\
\hline
\end{tabular}

ACL-QoL, Anterior Cruciate Ligament-Quality of Life scale; ACL-RSI, ACL-Return to Sport after Injury scale; FDR, false discovery rate; KOOS_QoL, Knee Osteoarthritis Outcome Scale Quality of Life domain; KOOS_Sport, Knee Osteoarthritis Outcome Scale sport domain; K-SES, Knee Self-Efficacy Scale; MHLC, Multidimensional Health Locus of Control scale; TSK, Tampa Scale for Kinesiophobia.

statistical criteria for inclusion in the final model $(B=0.59$, Wald $=27.7, \mathrm{p}<0.0001$, OR, 95\% $\mathrm{CI}=1.8,1.4$ to 2.2 ).

The final model $\left(\chi_{(5)}^{2}=48.3, \mathrm{p}<0.001\right.$; Nagelkerke $\left.\mathrm{R}^{2}=0.36\right)$ demonstrated that ACL-RSI score and time between injury and follow-up made significant independent contributions to explaining approximately $36 \%$ of the variance in returning to the preinjury sport or recreational activity. For every one point increase in ACL-RSI scale score, there was approximately twice the odds of returning to the preinjury activity. For every month increase in time to follow-up, the odds of returning to sport or recreational activity reduced by $3 \%$ (table 5 ). There were no significant interaction effects between ACL-RSI scale score and time to follow-up, age, sex or preinjury activity level; and no main effects of age, sex or preinjury activity level on returning to the preinjury sport or recreational activity (table 5).

\section{DISCUSSION}

Participants who had returned to their preinjury sport or recreational activity had more positive responses to the psychological outcomes, a higher knee-related quality of life and self-reported knee function, were more satisfied with their current knee function, and reported better knee function in sport and recreational activities compared with those who had not returned. The factor most strongly associated with returning to the preinjury activity was the ACL-RSI scale, which evaluates psychological

Table 5 Regression model of the relationship between returning to the preinjury sport or recreational activity, and psychological and demographic factors

\begin{tabular}{lccccl}
\hline Variable & B & SE & $\begin{array}{l}\text { Wald } \\
\text { statistic }\end{array}$ & $\begin{array}{l}\text { p } \\
\text { Value }\end{array}$ & OR $(95 \%$ Cl $)$ \\
\hline ACL-RSI & 0.67 & 0.12 & 31.2 & $<0.001$ & $1.95(1.5$ to 2.5$)$ \\
$\begin{array}{l}\text { Time to } \\
\text { follow-up }\end{array}$ & -0.03 & 0.02 & 4.7 & 0.03 & $0.97(0.94$ to 0.997$)$ \\
Age & -0.39 & 0.43 & 0.82 & 0.37 & $0.68(0.3$ to 1.6$)$ \\
Sex & 0.28 & 0.41 & 0.46 & 0.50 & $1.32(0.3$ to 1.6$)$ \\
$\begin{array}{l}\text { Preinjury activity level } \\
\text { Elite }\end{array}$ & & & & \\
Competitive & -0.61 & 0.57 & 1.15 & 0.28 & $0.54(0.2$ to 1.7$)$ \\
Recreational & -0.70 & 0.69 & 1.03 & 0.31 & $0.51(0.1$ to 1.9$)$ \\
\hline
\end{tabular}

ACL-RSI, Anterior Cruciate Ligament -Return to Sport after Injury scale. readiness to return to sport and recreational activity after ACL reconstruction. There were reduced odds of returning with increasing time between surgery and follow-up; and age, sex and preinjury activity level were not related to returning to the preinjury sport or recreational activity.

In the current study, psychological readiness to return to sport and recreational activity (measured with the ACL-RSI) was the factor most strongly associated with returning to the preinjury activity. In line with that, in two previous studies of competitive and recreational level athletes, the ACL-RSI has been identified as the best predictor of returning to the preinjury level sport at 12 months after ACL reconstruction. ${ }^{5} 34$ The scale is a condition-specific measure of psychological readiness (structured under the concepts of emotions, confidence and risk appraisal) and the current results provide further evidence of the construct validity of this scale. The specificity of this scale to the population, and the fact that the scale specifically addresses psychological factors related to performing sport and recreational activities may support its use as a key patient-reported outcome after ACL reconstruction.

The rate of return in the current study is similar to a previous study that evaluated the return to sport rate at 2-7 years following ACL reconstruction in an Australian population. ${ }^{4}$ In the Australian study, $45 \%$ of athletes had returned to their preinjury sport at follow-up. The authors also noted that some athletes returned to sport after reconstruction, then stopped participating. Promoting life-long participation in physical activity may be an important means of maintaining physical and mental health, ${ }^{35}$ and reducing chronic disease. ${ }^{36} 37$ Therefore, identifying the key factors that impact on returning to sport and recreation activities may be important so that physical activity promotion efforts may be directed towards addressing the factors relevant to those who do not return to activity. ${ }^{5} 34$

Previously reported minimum detectable change (MDC) scores for the KOOS Sport (range 5.8-12 points out of 100 points) and Quality of Life (range 7-7.2 points out of 100 points) domains, ${ }^{38}$ and the ACL-RSI (0.3 points out of 10 points) ${ }^{23}$ (MDC scores for other patient-reported outcomes have not been published) could suggest that the statistically significant differences in patient-reported outcomes, observed in the univariate analyses, between participants who had and had not returned to their preinjury activity may have clinical significance. 
However, while there was an association between returning to sport or recreational activity, and psychological factors including self-efficacy (measured with the K-SES) and appraisals of knee function (measured with the Sport domain of the KOOS) in the between-group comparison, these factors were not significant in the regression analysis. This could be because, in contrast to the ACL-RSI, the K-SES and KOOS_Sport scales are not sport-specific. Given that an individual's confidence in performance of tasks (self-efficacy) is theorised to be situation and task specific, ${ }^{39}$ and that performance in tasks such as squatting, kneeling, twisting and turning may be important for occupational functioning as well as for sport and recreation, this may explain the lack of association of the K-SES and KOOS_Sport with returning to sport and recreational activities in the regression analysis.

There are limited data regarding the reasons why people do not return to preinjury activity following ACL reconstruction. Some previous studies have shown that knee function and a fear of reinjury are frequently cited as the reasons for not returning after ACL reconstruction. ${ }^{4} 11 \quad 1340$ Around one in two participants in the current study who did not return to their previous activity cited a lack of confidence in the knee or fear of sustaining a new injury as the main reason for not returning. Around one in five reported that the main reason for not returning was poor knee function. It might be reasonable to expect that family or work commitments could contribute to people not returning to their previous activity. However, only approximately 1 in 10 participants who did not return to their previous activity reported work or family commitments as the primary reason for their non-return. This could suggest that the most important factors influencing the decision to return may be related to the individual's appraisal of their capacity to participate and the risks associated with participating. From the clinician's perspective, these findings may suggest that addressing psychological factors, including fear and confidence in postoperative rehabilitation, could have merit in helping people return to their preinjury sport or recreational activity. However, further research is required to test this hypothesis.

We found no influence of age on returning to sport or recreational activity. In contrast, recently, an association between younger age and an increased likelihood of returning to the previous activity has been demonstrated. ${ }^{4} 1341$ One possible explanation for this discrepancy could be that there are geographical differences in the treatment of acute ACL injuries. In Sweden, where the current study was conducted, patients with acute ACL injuries routinely complete a 3-6-month period of rehabilitation before a decision is made regarding ACL reconstruction. ${ }^{42}$ Reconstruction is typically recommended to young patients and to older patients with symptomatic instability. ${ }^{42}$ It could be speculated that older patients who elect for reconstruction following the completion of the initial rehabilitation programme may have greater motivation to return to their previous sport or recreational activity; and this may help to explain why the rate of return to activity was similar across the age groups.

Most of the previous literature has evaluated physical impairments after ACL reconstruction. Strength of the current study is that by evaluating several psychological factors, appraisal of knee function and demographic factors, and using a multivariable analysis, it takes into account the multifactorial nature of returning to the preinjury sport and recreational activity after ACL reconstruction. This is important given that previous research has tended to evaluate single factors. In addition, the current study examined the reasons for not returning to the preinjury activity.

A limitation of this study was that only $59 \%$ of potential participants responded to the battery of patient-reported outcomes. It is possible that, given the number of patient-reported outcomes included in the battery, some participants were deterred from completing it. Non-responders may have had a different rate of return to the preinjury sport and recreational activity, responses to the psychological outcomes and appraisal of knee function, than those who responded to the battery of outcomes. However, this response rate is comparable to a previous report of return to sport rates at 2-7 years after ACL reconstruction surgery, ${ }^{4}$ and above the $50 \%$ minimum suggested to reduce bias. ${ }^{43} 44$

The population in the current study is heterogeneous in terms of preinjury sport and recreational activity participation. However, it is important to note that the sport and recreational activities participated in reflect the typical distribution of activities played at the time of ACL injury, reported in the Swedish National ACL register. ${ }^{45}$ Activities that place higher demands on the operated knee, such as competitive football, may be more challenging for people to return to in comparison with activities such as recreational cycling that place lower demands on knee function. ${ }^{46}$ Further research is required to explore differences in the rates of return to the preinjury activity following ACL reconstruction in different sport and recreational activities with different physical demands. ${ }^{46}$ The cross-sectional design of the current study means that it is not possible to determine whether positive psychological factors and better appraisal of knee function predict returning to the pre-injury sport and recreational activity. In addition, we chose to focus on one group of nonphysical factors, psychological factors, as it was beyond the scope of this study to investigate all the factors that could impact on returning to sport and recreational activities (physical and non-physical). Therefore, consideration of the impact of other factors not evaluated in the current study may be warranted in future prospective studies.

As time from surgery to follow-up increased, the odds of returning to the pre-injury activity decreased, which may suggest that for some, other commitments took priority over participating in sport and recreational activity. It is also possible that some participants may have returned to sport or recreation early after surgery and ceased participation before follow-up or changed to participate in a different activity. However, further research is necessary to confirm these hypotheses.

\section{What are the new findings?}

- Psychological readiness to return to sport (measured with the Anterior Cruciate Ligament-Return to Sport after Injury (ACL-RSI) scale) was the factor most strongly associated with returning to the preinjury sport or recreational activity after $\mathrm{ACL}$ reconstruction.

- Age, sex and preinjury activity level were not associated with returning to the preinjury sport or recreational activity.

- The most common reasons given by participants for not returning to the preinjury activity were: not trusting the knee, fear of another injury and poor knee function. 


\section{How might it impact on clinical practice in the near future?}

- A stronger and more systematic emphasis on addressing psychological readiness to return to activity in postoperative rehabilitation programmes could be warranted to help improve returning to activity after $\mathrm{ACL}$ reconstruction.

- Patients reporting a lack of confidence in the knee or fear of sustaining a new injury may be at increased risk of not returning to their preinjury sport or recreational activity, and could require additional support during rehabilitation.

- Clinicians may wish to consider the use of the ACL-RSI scale as a key patient-reported outcome after $\mathrm{ACL}$ reconstruction.

Acknowledgements The authors thank Henrik Magnusson at Linköping University for statistical support; and Professor Gerhard Andersson at Linköping University for advice on interpretation of the results.

Contributors All authors contributed to the design of the study. AÖ was responsible for participant recruitment, and JK and AÖ for data collection. CLA, JK and $A O ̈$ analysed the data. CLA and AÖ drafted the manuscript, and JK, HG, ST and KEW revised it for important intellectual content. All authors approved the final manuscript. CLA is responsible for the overall content as the guarantor.

Competing interests None.

Ethics approval Regional Ethics Committee at Linköping University (approval number 2012/425-32).

Provenance and peer review Not commissioned; externally peer reviewed.

\section{REFERENCES}

1 Brand E, Nyland J. Patient outcomes following anterior cruciate ligament reconstruction: the influence of psychological factors. Orthopedics 2009;32: $335-41$

2 McCullough KA, Phelps KD, Spindler KP, et al. Return to high school- and college-level football after anterior cruciate ligament reconstruction: a multicenter orthopaedic outcomes network (MOON) cohort study. Am I Sports Med 2012:40:2523-9

3 Ardern CL, Webster KE, Taylor NF, et al. Return to sport following anterior cruciate ligament reconstruction surgery: a systematic review and meta-analysis of the state of play. Br J Sports Med 2011;45:596-606.

4 Ardern $\mathrm{CL}$, Taylor NF, Feller JA, et al. Return to sport outcomes at 2 to 7 years following anterior cruciate ligament reconstruction surgery. Am J Sports Med 2012;40:41-8.

5 Ardern $\mathrm{CL}$, Taylor NF, Feller JA, et al. Psychological responses matter in returning to preinjury level of sport after anterior cruciate ligament reconstruction surgery. Am J Sports Med 2013:41:1549-58.

6 Ardern $\mathrm{CL}$, Webster $\mathrm{KE}$, Taylor $\mathrm{NF}$, et al. Return to the preinjury level of competitive sport following anterior cruciate ligament reconstruction surgery: two thirds of patients have not returned by 12 months following surgery. Am I Sports Med 2012;39:538-43.

7 Podlog L, Eklund R. The psychosocial aspects of a return to sport following serious injury: a review of the literature from a self-determination perspective. Psychol Sport Exerc 2007;8:535-66.

8 Ardern CL, Taylor NF, Feller JA, et al. A systematic review of the psychological factors associated with returning to sport following injury. Br I Sports Med 2013;47:1120-6.

9 Ardern CL, Taylor NF, Feller JA, et al. Fifty-five per cent return to competitive sport following anterior cruciate ligament reconstruction surgery: an updated systematic review and meta-analysis including aspects of physical functioning and contextual factors. Br J Sports Med 2014;48:1543-52.

10 Thomeé $\mathrm{P}$, Währborg $\mathrm{P}$, Börjesson $\mathrm{M}$, et al. Self-efficacy of knee function as a pre-operative predictor of outcome 1 year after anterior cruciate ligament reconstruction. Knee Surg Sports Traumatol Arthrosc 2008;16:118-27.

11 Kvist J, Ek A, Sporrstedt K, et al. Fear of re-injury: a hindrance for returning to sports after anterior cruciate ligament reconstruction. Knee Surg Sports Traumatol Arthrosc 2005;13:393-7.

12 Tripp DA, Ebel-Lam A, Stanish W, et al. Fear of reinjury, negative affect, and catastrophizing predicting return to sport in recreational athletes with anterior cruciate ligament injuries at 1 year postsurgery. Rehabil Psychol 2007:52:74-81.
13 Flanigan DC, Everhart JS, Pedroza A, et al. Fear of reinjury (kinesiophobia) and persistent knee symptoms are common factors for lack of return to sport after anterior cruciate ligament reconstruction. Arthroscopy 2013;29:1322-9.

14 Österberg A, Kvist J, Dahlgren M. Ways of experiencing participation and factors affecting the activity level after nonreconstructed anterior cruciate ligament injury: a qualitative study. I Orthop Sports Phys Ther 2013;43:172-83.

15 Kocher MS, Steadman JR, Briggs KK, et al. Assessment of ligament stability and subjective assessment of symptoms and function after anterior cruciate ligament reconstruction. Am J Sports Med 2004;32:629-34.

16 Muneta T, Sekiya I, Ogiuchi T, et al. Objective factors affecting overall subjective evaluation of recovery after anterior cruciate ligament reconstruction. Scand I Med Sci Sports 1998;8:283-9.

17 Sernert N, Kartus J, Köhler K, et al. Analysis of subjective, objective and functional examination tests after anterior cruciate ligament reconstruction. a follow-up of 527 patients. Knee Surg Sports Traumatol Arthrosc 1999;7:160-5.

18 Outerbridge RE. The etiology of chondromalacia patellae. J Bone Joint Surg Br 1961;43-B:752-7.

19 Tegner Y, Lysholm J. Rating systems in the evaluation of knee ligament injuries. Clin Orthop Relat Res 1985;198:43-9.

20 Fältström $\mathrm{A}$, Hägglund $\mathrm{M}$, Kvist J. Patient-reported knee function, quality of life, and activity level after bilateral anterior cruciate ligament injuries. Am I Sports Med 2013:41:2805-13.

21 Thomeé $\mathrm{P}$, Währborg $\mathrm{P}$, Börjesson $\mathrm{M}$, et al. A new instrument for measuring self-efficacy in patients with an anterior cruciate ligament injury. Scand I Med Sci Sports 2006;16:181-7.

22 Wallston KA, Stein MJ, Smith CA. Form C of the MHLC Scales: a condition-specific measure of locus of control. J Pers Assess 1994;63:534-53.

23 Kvist J, Österberg A, Gauffin H, et al. Translation and measurement properties of the Swedish version of ACL-Return to Sports after Injury questionnaire. Scand I Med Sci Sports 2013;23:568-75.

24 Webster KE, Feller JA, Lambros C. Development and preliminary validation of a scale to measure the psychological impact of returning to sport following anterior cruciate ligament reconstruction surgery. Phys Ther Sport 2008;9:9-15.

25 Kori SH, Miller RP, Todd DD. Kinesiophobia: a new view of chronic pain behaviour. Pain Manag 1990;3:35-43

26 Roos EM, Roos HP, Lohmander LS, et al. Knee Injury and Osteoarthritis Outcome Score (KOOS) — development of a self-administered outcome measure. J Orthop Sports Phys Ther 1998:28:88-96

27 Mohtadi N. Development and validation of the quality of life outcome measure (questionnaire) for chronic anterior cruciate ligament deficiency. Am I Sports Med 1998:26:350-9.

28 Benjamini $Y$, Hochberg $Y$. Controlling the false discovery rate: a practical and powerful approach to multiple testing. J R Stat Soc Ser B 1995;57:289-300.

29 Glickman ME, Rao SR, Schultz MR. False discovery rate control is a recommended alternative to Bonferroni-type adjustments in health studies. I Clin Epidemiol 2014;67:850-7

30 Hoad K, Monks T. A note of the use of multiple comparison scenario techniques in education and practice. 2011 Winter Simulation Conference; 11-14 December 2011; Phoenix, AZ.

31 Perneger TV. What's wrong with Bonferroni adjustments. BMJ 1998;316:1236.

32 Menard SW. Applied logistic regression analysis. 2nd edn. Thousand Oaks, CA: SAGE, 2001.

33 Tabatchnick BG, Fidel LS. Using multivariate statistics. 4th edn. Needham Heights, MA: Allyn \& Bacon, 2001

34 Langford J, Webster KE, Feller JA. A prospective longitudinal study to assess psychological changes following anterior cruciate ligament reconstruction surgery. $\mathrm{Br}$ J Sports Med 2009:43:377-88.

35 Andrew N, Wolfe $\mathrm{R}$, Cameron $\mathrm{P}$, et al. The impact of sport and active recreation injuries on physical activity levels at 12 months post-injury. Scand I Med Sci Sports 2014; 24:377-85

36 Rönn T, Volkov P, Davegårdh C, et al. A six months exercise intervention influences the genome-wide DNA methylation pattern in human adipose tissue. PLoS Genet 2013:9:e1003572.

37 Williams PT. Vigorous exercise, fitness and incident hypertension, high cholesterol, and diabetes. Med Sci Sports Exerc 2008;40:998-1006.

38 Collins NJ, Misra D, Felson DT, et al. Measures of knee function. Arthritis Care Res 2011:63:S208-28

39 Bandura A. Self-efficacy: toward a unifying theory of behavioral change. Psychol Rev 1977:84:192-215.

40 Lentz TA, Zeppieri G, Tillman SM, et al. Return to preinjury sports participation following anterior cruciate ligament reconstruction: contributions of demographic, knee impairment, and self-report measures. J Orthop Sports Phys Ther 2012:42:893-901.

41 Brophy RH, Schmitz L, Wright RW, et al. Return to play and future ACL injury risk after $\mathrm{ACL}$ reconstruction in soccer athletes from the Multicenter Orthopaedic Outcomes Network (MOON) group. Am I Sports Med 2012;40:2517-22. 
42 Frobell $\mathrm{RB}$, Roos $\mathrm{EM}$, Roos $\mathrm{HP}$, et al. A randomized trial of treatment for acute anterior cruciate ligament tears. N Engl J Med 2010;363:331-42.

43 Dillman DA. Mail and telephone surveys: the total design method. New York, NY: Wiley, 1978.

44 Rea LM, Parker RA. Designing and conducting survey research: a comprehensive guide. San Francisco, CA: Jossey-Bass, 1997.
45 Røtterud JH, Sivertsen EA, Forssblad M, et al. Effect of gender and sports on the risk of full-thickness articular cartilage lesions in anterior cruciate ligament-injured knees. A nationwide cohort study from Sweden and Norway of 15783 patients. Am J Sports Med 2011:39:1387-94.

46 Warner SJ, Smith MV, Wright RW, et al. Sport-specific outcomes after anterior cruciate ligament reconstruction. Arthroscopy 2011;27:1129-34. 